\title{
Remote sensing of aerosol in the terrestrial atmosphere from space: new missions
}

\author{
G. Milinevsky ${ }^{1,2 *}$, Ya. Yatskiv ${ }^{1}$, O. Degtyaryov ${ }^{3}$, I.Syniavskyi $^{1}$, Yu. Ivanov ${ }^{1}$, \\ A. Bovchaliuk ${ }^{1,4}$, M. Mishchenko ${ }^{5}$, V. Danylevsky ${ }^{2}$, M.Sosonkin ${ }^{1}$, V. Bovchaliuk ${ }^{2,4}$ \\ ${ }^{1}$ Main Astronomical Observatory of NAS of Ukraine, 27 Akad. Zabolotnoho Str., 03680 Kyiv, Ukraine \\ 2 Taras Shevchenko National University of Kyiv, 64/13 Volodymyrska Str., 01601 Kyiv, Ukraine \\ ${ }^{3}$ Yangel Yuzhnoye State Design Office of State Space Agency of Ukraine, \\ 3 Krivorozhskaya Str., 49008 Dnipropetrovsk, Ukraine \\ ${ }^{4}$ Laboratoire d'Optique Atmosphérique, CNRS - Université de Lille 1, Villeneuve d'Ascq, France \\ ${ }^{5}$ NASA Goddard Institute for Space Studies, 2880 Broadway, NY 10025, New York, USA
}

\begin{abstract}
The distribution and properties of atmospheric aerosols on a global scale are not well known in terms of determination of their effects on climate. This mostly is due to extreme variability of aerosol concentrations, properties, sources, and types. Aerosol climate impact is comparable to the effect of greenhouse gases, but its influence is more difficult to measure, especially with respect to aerosol microphysical properties and the evaluation of anthropogenic aerosol effect. There are many satellite missions studying aerosol distribution in the terrestrial atmosphere, such as MISR/Terra, OMI/Aura, AVHHR, MODIS/Terra and Aqua, CALIOP/CALIPSO. To improve the quality of data and climate models, and to reduce aerosol climate forcing uncertainties, several new missions are planned. The gap in orbital instruments for studying aerosol microphysics has arisen after the Glory mission failed during launch in 2011. In this review paper, we describe several planned aerosol space missions, including the Ukrainian project Aerosol-UA that obtains data using a multi-channel scanning polarimeter and wide-angle polarimetric camera. The project is designed for remote sensing of the aerosol microphysics and cloud properties on a global scale.
\end{abstract}

Key words: atmosphere, aerosol, cloud, climate, polarimeter

\section{INTRODUCTION}

The distribution and properties of atmospheric aerosols on a global scale have not yet been studied sufficiently in order to be useful in comprehensive climate modelling. Aerosol climate impacts are comparable to those of the greenhouse gases, but are more difficult to measure, especially with respect to aerosol microphysical properties and estimates of anthropogenic component effect. Accurate quantitative evaluation of these effects and, especially, of their anthropogenic part, are still not well developed. This makes it difficult to provide accurate climate change modelling and formulate scientifically justified social and economic programs. There are number of satellite missions studying aerosol distribution in the terrestrial atmosphere, such as MISR/Terra, OMI/Aura, AVHHR, MODIS/Terra and Aqua, POLDER/PARASOL, CALIOP/CALIPSO (see e. g., $[23,25,30,33]$ ). To improve the quality of data and climate models, and to reduce aerosol climate forcing uncertainties, several new missions are planned. After the failed launch of the Glory mission [29] in 2011, the gap in aerosol orbital instruments has appeared, as similar missions are not planned until 2019 at the earliest. NASA's Aerosol Cloud Ecosystems (ACE) mission is planned to reduce the uncertainty regarding climate forcing in aerosol-cloud interactions and ocean ecosystem carbon dioxide uptake [30]. The ACE mission is expected to be launched in 2024, preceded by the Pre-ACE mission in 2019 or later. After a successful nine years of operation of the POLDER/PARASOL aerosol space mission of CNES, an advanced aerosol polarimeter is planned for launch in 2020 or later in the framework of the project 3MI [1]. Two more instruments/missions are planned, namely, the Multiangle Spectro Polarimetric Imager (MSPI) as a possible instrument for an ACE mission [7], and the SPEX instrument [39] designed by the NWO-SRON Netherlands Institute for Space Research.

A comprehensive review of the multi-angle spectro-polarimetric technique for aerosol study from a satellite is given in [22]. In this paper, several planned aerosol missions are considered with the

\footnotetext{
*genmilinevsky@gmail.com

(C) G. Milinevsky, Ya. Yatskiv, O.Degtyaryov, I. Syniavskyi, Yu. Ivanov,

A. Bovchaliuk, M. Mishchenko, V.Danylevsky, M. Sosonkin, V. Bovchaliuk, 2015
} 
main focus on the Ukrainian space project AerosolUA, with two instruments: a multi-channel scanning polarimeter and a wide-angle polarimetric camera [40].

\section{AEROSOL CLOUD ECOSYSTEMS MISSION}

The Aerosol-Cloud-Ecosystem (ACE) mission of NASA has been discussed since 2007 and has as its goal to answer questions on aerosols, clouds, and global ocean ecosystems interaction ${ }^{1}$. Aerosols measured by ACE will cover anthropogenic and natural origins with distinguishing aerosol types, optical properties, and size. The mission should provide two decade surveys, in particular aerosol, to estimate indirect effects of aerosols through modification of cloud creation, to reduce the uncertainty in aerosolcloud interaction, as well as the uncertainty in the impact of aerosols on climate change. The main scientific instruments for the mission are planned to include equipment for (1) aerosol and cloud top heights, aerosol properties measurements (lidar); (2) cloud and precipitation microphysics structure measurements (radar); (3) aerosol optical properties and aerosol type measurements (polarimeter). Additionally, a spectrometer for ocean colour, microwave radiometers for cloud ice, precipitation, and water measurements, and a microwave sounder for temperature and humidity measurements, will be onboard the mission.

One of the candidate instruments for aerosol microphysical studies to be used on the ACE mission, is the Aerosol Polarimetry Sensor (APS), discussed in $[4,29]$. APS is a scanning multispectral polarimeter with narrow field-of-view in nadir and a multiangle scene view by a scan along track. This instrument previously was designed and created for the NASA Glory mission, which has been unsuccessful due to a failed launch in March $2011^{2}$. APS instrument data products include all parameters that characterize the microphysical and optical properties of particles: aerosol optical thickness, aerosol particle effective radius and size distribution, spectral refractive index, single scattering albedo, and aerosol morphology (all for fine and coarse modes). For cloud properties APS will provide information on the cloud thermodynamic phase, cloud droplet effective radius, variance of size distribution, and cloud liquid droplet optical thickness [29]. These data will enable to separate natural and human-caused aerosols, investigate black carbon soot and other aerosols as atmospheric constitutions for climate change. The main feature of APS instrument is polarization accuracy that reaches a level better than $0.15 \%$ in each spectral channel according to the radiances test [4]. This accuracy allows to separate aerosols by refractive index in type and origin. The polarization accuracy of APS is provided by a comprehensive set of on-board calibration for each scan of the atmosphere.

Multiangle SpectroPolarimetric Imager (MSPI) is also considered as an aerosol polarimeter instrument for the ACE mission. MSPI is a new type of wide-angle polarimetric camera with polarimetric precision better than $0.5 \%$ and time resolution of $>0.04 \mathrm{~s}$. The camera consists of a three-mirror offaxis anastigmatic telescope, and images are created by scanning in pushbroom mode. The polarization is measured using dual photoelastic modulators set between quarterwave plates (Fig. 1) and assembly of linear polarizers and dielectric filters set above the focal plane of the sensor array [8,33]. MSPI provides images at polarization wavelengths 470,660 , $865 \mathrm{~nm}$ with accuracy $<0.3 \%$ in Stokes parameters $\mathrm{I}, \mathrm{Q} / \mathrm{I}$ and $\mathrm{U} / \mathrm{I}$, radiometric accuracy $<3 \%$, and a field of view of $30^{\circ}$ with a resolution of $0.02^{\circ}$. Two MSPI imagers, one ground-based and one for aircraft flights, are in operation [8]. Instruments are providing polarimetric images with approximately 1500 times5100 pixel resolution. One more MSPI instrument under development will allow registering a scene at wavelength to $2.1 \mu \mathrm{m}$. MSPI polarimetric imager provides multispectral polarimetry with capability for retrieving key aerosol parameters in the atmosphere. Due to the uncertainties in the aerosols contribution that are larger than the other constituents combined in the Earth atmosphere energy balance, the MSPI was developed for the ACE mission in order to reduce these uncertainties $[6,9,10]$.

PACS multi-angle imaging polarimeter. Passive Aerosol and Clouds Suite (PACS) polarimeter was developed for cloud and aerosols investigations [14] and is a new type of imaging multiangle polarimetric instruments designed to study microphysics of aerosol and cloud particles. The PACS polarimeter is designed as a wide field-of-view multispectral polarimeter for instantaneous measurements in three linear polarization channels to retrieve three Stokes parameters. Observations at the wavelengths at 470, $550,675,760$ and $875 \mathrm{~nm}$ in the three linear polarization channels provide polarimetric accuracy sufficiently high for aerosol microphysical study. The PACS polarimeter was tested aboard an aircraft during the PODEX experiment and registered data on aerosol and clouds over various types of Earth surfaces $^{3}$.

\section{SPEX SPECTROPOLARIMETER}

\section{INSTRUMENT}

The SPEX (Spectropolarimeter for Planetary Exploration) instrument was designed in NWO-SRON Netherlands Institute for Space Research, and is yet

\footnotetext{
${ }^{1}$ http://dsm.gsfc.nasa.gov/ace/

${ }^{2}$ http: //www.nasa.gov/mission_pages/Glory/news/mishap-board-report.html

${ }^{3}$ http: //www .nasa.gov/topics/earth/features/qa-starr.html
} 
another novel spectropolarimeter with high polarization measurement accuracy $[15,35,39]$. For the purpose of studying aerosol microphysics, the polarization measurement must have an accuracy of better than $0.1 \%$, and a large field of view is needed for global coverage. The SPEX instrument can achieve these demands in polarimetric aerosol remote sensing. SPEX is built on a new technique for polarization measurements using several birefringent crystals and spectral modulation the radiance of scattered sunlight [36]. The spectral modulation amplitude and phase are proportional to the degree and angle of linear polarization. Two modulated spectra are produced with a 180 degree phase shift between modulations. The sum of the two spectra produces a modulation-free high resolution scattered sunlight radiance spectrum [36]. In this way, a SPEX polarimeter provides a $0.1 \%$ linear polarization polarimetric accuracy, which enables the retrieval of aerosol properties for climate modelling: optical thickness, size, shape, refractive index, and single scattering albedo.

\section{ADVANCED AEROSOL POLARIMETER IN THE PROJECT $3 \mathrm{MI} / \mathrm{EPS}-\mathrm{SG}$}

The POLDER-1, POLDER-2 and PARASOL polarimeter missions which have been in operation since 1996, have shown the value of using polarisation for studying atmospheric aerosols [37]. The development of the POLDER instrument features to increase the capabilities for polarization measurements the Multi-directional, Multi-polarization and Multispectral Instrument (3MI) is proposed [1]. The improvement of the POLDER parameters will be done by increasing the spectral range from UV (ultraviolet) to SWIR (shortwave infrared), improving the spatial resolution and increasing the swath dimension of the instrument. 3MI will have a large swath (field of view $114^{\circ}$ ) and a better spatial resolution, increased to $2 \mathrm{~km}$ and $4 \mathrm{~km}$ for the VIS and SWIR channels respectively in comparison to the $10 \mathrm{~km}$ spatial resolution for POLDER. Addition of polarization in the SWIR channel will provide information for aerosol coarse particles over land and will help to extract the aerosol size distribution with total, fine, coarse, spherical and non-spherical modes. Improved resolution and additional spectral channels will enable better cloud detection. The concept of the 3MI instrument [1] is shown in Fig. 2. The 3MI polarimeter will help improve the daily global coverage, and perform multi-angle measurements, because of a larger swath along and across track directions [1]. The 3MI mission will provide the set of aerosol parameters: aerosol optical thickness and particle size for fine, coarse and total modes with horizontal resolution better than $10 \mathrm{~km}$, Angstrom exponent, refractive and non-sphericity index, aerosol absorption and height index $[1,24]$. All these param- eters will be obtained in near real time. The 3MI instrument is planned for the EPS-SG (EUMETSAT Polar System-Second Generation) project to allow comprehensive Earth atmosphere aerosol investigation for the coming 20 years in 2021-2040.

\section{AEROSOL-UA MISSION}

\section{DESIGN OF THE SCANPOL POLARIMETER}

The scanning polarimeter ScanPol of the AerosolUA mission is based on the concept of the NASA's Glory satellite project $[4,29]$. The purpose of the Glory mission was to monitor the spatial and temporal distribution of the main characteristics of tropospheric and stratospheric aerosols and clouds in the atmosphere, using the Aerosol Polarimetry Sensor (APS) [29]. The ScanPol is also a continuous scanning polarimetric instrument. ScanPol is designed to make along-track multi-angle observations of spectral polarization and radiance scene for the Earth's surface and atmospheric components. This multichannel instrument has the capability to collect polarized radiometric data scattered from aerosols and clouds in a wide spectral range. The number of spectral channels in the ScanPol is reduced to six as compared with polarimeter APS, however, a new spectral channel at $370 \mathrm{~nm}$ is added. The polarimeter ScanPol allows to measure Stokes parameters I, Q, $\mathrm{U}$ within the spectral range from the near ultraviolet (UV) to the short-wave infrared (SWIR) spectral band in a wide range of phase angles. We expect the photometric accuracy of ScanPol to be approximately $4 \%$, and the polarimetric accuracy to be approximately $0.2 \%$.

The polarimeter module of the ScanPol is composed of two major modules: the mirror scanning system and the optical module (Fig. 3). The twomirror scanning system is designed to direct solar radiation scattered by the investigated area of the atmosphere-surface system. The scanning system has a pair of mirrors that form a neutral polarization combination. Mirrors rotate at a speed of approximately $40 \mathrm{rpm}$ in the plane of the spacecraft orbit. The ScanPol viewing angle range on the Earth is about $\pm 60^{\circ}$ from nadir direction.

The optical module includes four optical units: VIS-1, VIS-2, IR-1, and IR-2 (Fig. 3). Each VIS unit consists of three spectral channels in the spectral range $370-555 \mathrm{~nm}$ and each IR unit includes 3 spectral channels in the spectral range $865-1610 \mathrm{~nm}$ (see Fig. 3).

The spectral channels of the VIS units are used to study (1) the tropospheric aerosol absorption capacity and its vertical distribution (channel $370 \mathrm{~nm}$, $\Delta \lambda=10 \mathrm{~nm}),(2)$ the aerosol over the ocean and the land surface ( $410 \mathrm{~nm}, \Delta \lambda=20 \mathrm{~nm})$, and the colour of the ocean and sensing aerosol ( $555 \mathrm{~nm}, \Delta \lambda=20 \mathrm{~nm})$.

The optical IR units spectral channels are required (1) for sensing aerosol over ocean and 
land (channel $865 \mathrm{~nm}, \Delta \lambda=40 \mathrm{~nm}$ ), (2) for separation the signals from cirrus clouds and stratospheric/tropospheric aerosols, and to separate stratospheric aerosols caused by major volcanic eruptions $(1378 \mathrm{~nm}, \Delta \lambda=40 \mathrm{~nm})$, (3) for assessing the contribution of the Earth's surface to the measured signal over land $(1610 \mathrm{~nm}, \Delta \lambda=40 \mathrm{~nm})$. The wavelength at the maximum of the filter passband and its bandwidth $\Delta \lambda$ (i. e., full-width at half-maximum) for each channel is shown in brackets.

The optical layout of the instrument and opticalmechanics unit assembled with a scanning system general view are shown in Figs. 3 and 4, respectively. Each of the optical units consists of the following optical elements sequenced from the mirror scanning system: input lens which forms an intermediate image of the object; field diaphragm (Fig. 3, not shown); collimator; Wollaston prism splitting rays into two components with the $\mathrm{S}$ and $\mathrm{P}$ orthogonal polarizations and thereby performing the function of analyzer; a system of dichroic mirrors and interference filters with spectral range $\Delta \lambda$; and camera lenses forming two images $(\mathrm{S}$ and $\mathrm{P}$ ) on the detector.

\section{WIDE-ANGLE MULTISPECTRAL CAMERA}

The information on cloud conditions and the Earth's surface, including geographical coordinates of the scene, is need for correct interpretation ScanPol data. In the concept of the Aerosol-UA mission, the multispectral wide-angle polarimetric cameraimager MSIP was included for that purposes. MSIP will serve to collect images on state of the atmosphere (cloud distribution) and surface (surface homogeneity, land surface, sea surface) in the area of the ScanPol polarimeter measurements. MSIP will help to retrieve the aerosol optical depth in four spectral channels $410,555,865$, and $936 \mathrm{~nm}(\Delta \lambda=20-40 \mathrm{~nm})$, and estimate the polarization properties by registering three Stokes parameters simultaneously. Four independent identical camera units will collect images with a field-of-view $60^{\circ} \times 60^{\circ}(800 \times 800 \mathrm{~km})$ with a spatial resolution of approximately $4 \mathrm{~km}$. The aperture diameter of the camera is $22 \mathrm{~mm}$, the total length is $300 \mathrm{~mm}$, and the detector size is $20 \times 20 \mathrm{~mm}$. The unit of the polarization analysis is based on birefringent prism or polarizing film. The polarization accuracy for camera should be better than $1 \%$. That will be reached as expected by using intercalibration within the ScanPol data onboard the satellite. The multispectral polarimetric camera-imager MSIP can be the main instrument onboard Aerosol-UA satellite mission if the task of polarimetric calibration will be solved.

\section{GROUND-BASED VALIDATION}

Validation of aerosol space missions with groundbased measurements is provided using networks of special instruments. Most developed tools are lidar network EARLINET [32] and sunphotometer networks AERONET [16, 17], SKYNET [20], Precision Filter Radiometer (GAW-PFR) [21]. Validation of the Aerosol-UA mission data by groundbased measurements will be performed using the technique, equipment, and experience of the sunphotometer AERONET network [16, 27, 28], where the international scientific AERONET community will be involved to participate in the Aerosol-UA mission support. Particularly, the aerosol properties data obtained from Ukraine AERONET sites, equipped with CIMEL CE318 sunphotometers, have enabled to determine the aerosol seasonal behaviour in the atmosphere over Ukraine $[3,27]$. Validation of the ScanPol and MSIP space-born polarimeters data will be performed by comparison of the columnar spectral aerosol optical depth (AOD) and columnar aerosol particles properties obtained from simultaneous measurements of the optical characteristics of the same air mass by both the orbital ScanPol polarimeter and ground-based sunphotometer. The "simultaneity (coincidence)" criterion of the spaceborn and ground-based measurements has been determined, for example, in $[5,13,18,19]$. But there are specific problems in coincident ground-based and satellite measurements of the same air mass optical properties in the case of the ScanPol, similar to the case of the Glory/APS and CALIOP, due to a very narrow field of view of these instruments [26, 31]. In order to acquire as much data as possible, it is planned to use the CIMEL sunphotometers for mobile ground-based measurements of the aerosol properties in the sites located close to Aerosol-UA ground trace and close to its passage time. Also, the portable sunphotometer Microtops II will be used for mobile spectral AOD measurements in accordance to AERONET programme. This portable sunphotometer is used successfully for aerosol measurements from ships in various sites of the planet as a part of AERONET [34].

Using the mobile AERONET site will enable to perform coincident space-based and ground-based measurements very close to the Aerosol-UA ground trace, and to enhance the satellite data accuracy. Experiences in aerosol properties mobile measurements acquired earlier in various regions of Ukraine (see [2, 28]) allow us to fine-tune the experimental technique for ground-based validation of aerosol studies in the Earth's atmosphere by the Aerosol-UA mission instruments.

Also in situ measurements of the aerosol particle properties with special instruments such as integrating nephelometers and particle size spectrometers will be useful in the locations close to the AerosolUA traces, particularly installed on the flying vehicles that allow performing measurements on various heights over land. The ground-based validation program for the Aerosol-UA mission is based on the proposals earlier stated for NASA's Glory mission project validation [38]. 


\section{CONCLUSIONS}

Several aerosol missions are prepared for comprehensive study of aerosol in the Earth's atmosphere, in order to reduce gaps in knowledge on aerosol properties, microphysics, and origin. The most promising results from the Pre-ACE mission experiment follow from NASA's Polarimeter Definition Experiment (PODEX) in 2013 using the AirMSPI instrument [9]. The instrumentation for the aerosol space experiment Aerosol-UA has been developed, in particular, the ScanPol polarimeter has been designed. The components of the ScanPol polarimeter have been computer-designed and prototyped, including the optical-mechanical and electronic assemblies, as well as the scanning mirror controller. Initial technical requirements have been developed for the elements of spectral selection; in particular, dichroic mirrors and interference filters have been developed. The ScanPol polarimeter opticalmechanical unit equipped with a multichannel optical information reader has been built and prepared for a laboratory test. A preliminary investigation of the scanning mirror unit has been performed. The results have shown that the proposed combination of mirrors allows compensating the reflection polarization from the mirror metal coatings. The optical layout of the multispectral wide-angle polarimetric camera-imager MSIP has been modelled. The imager MSIP will serve as a monitor of weather conditions and to register polarimetric images along the ScanPol polarimeter ground track. We expect to process the data from ScanPol polarimeter and MSIP multi-spectral polarimetric camera using the new GRASP inversion algorithm that shows promising results for obtaining multi-instrument aerosol measurements [11, 12]. Methods for the validation of satellite data using a mobile sunphotometer station, as well as for the calibration of aerosol polarimetry, have been further developed.

\section{ACKNOWLEDGEMENTS}

The work was supported by the Special Complex Program for Space Research 2012-2016 of the National Academy of Sciences of Ukraine (NASU), project PICS 2013-2015 of CNRS and NASU, and projects $11 \mathrm{BF} 051-01-12$ and $11 \mathrm{BF} 023-01$ of the Taras Shevchenko National University of Kyiv. We thank B. Holben (NASA/GSFC) for managing the AERONET program and its sites.

\section{REFERENCES}

[1] Bréon F.-M., Boucher O., Lifermann A. et al. 2011, 'The $3 M I$ mission for operational monitoring of aerosols from $E P S-S G$, CNES Report

[2] Bovchaliuk V., Bovchaliuk A., Milinevsky G. et al. 2013, Advances in Astronomy and Space Physics, 3, 46

\footnotetext{
${ }^{4}$ http: //acemission.gsfc.nasa.gov/ACE_SWG_2014.html
}

[3] Bovchaliuk A., Milinevsky G., Danylevsky V. et al. 2013, Atmos. Chem. Phys., 13, 6587

[4] Cairns B. 'Aerosol Polarimetry Sensor (APS), Design Summary, Performance and Potential Modifications', 2014, ACE 2014, Science Working Group Workshop Documents $^{4}$

[5] Chu D. A., Kaufman Y. J., Ichoku C. et al. 2002, Geophys. Res. Lett., 29, 8007

[6] Diner D. 2014, 'Status of Multiangle SpectroPolarimetric Imager (MSPI) technology development', ACE 2014 Science Working Group Workshop Documents ${ }^{4}$

[7] Diner D. J., Davis A., Hancock B. et al. 2007, Applied Optics IP, 46, 8428

[8] Diner D. J., Davis A., Hancock B. et al. 2010, Appl. Opt., 49, 2929

[9] Diner D. J., Garay M. J., Kalashnikova O. V. et al. 2013, Proc. SPIE, 8873, 88730B

[10] Diner D. J., Xu F., Garay M. J. et al. 2013, Atmospheric Measurement Techniques, 6, 2007

[11] Dubovik O., Herman M., Holdak A. et al. 2011, Atmospheric Measurement Techniques, 4, 975

[12] Dubovik O., Lapyonok T., Litvinov P. et al. 2014, SPIE Newsroom, DOI: 10.1117/2.1201408.005558

[13] Fan X., Goloub Ph., DeuzéJ.-L. et al. 2008, Remote Sens. Environ., 112, 697

[14] Fernandez Borda R. A. \& Martins J. 2013, American Geophysical Union, Fall Meeting 2013, abstract \#A34E05

[15] Hasekamp O. P. \& Landgraf J. 2007, Applied Optics IP, 46,3332

[16] Holben B. N., Eck T.F., Slutsker I. et al. 1998, Remote Sens. Environ., 66, 1

[17] Holben B. N., Tanré D., Smirnov A. et al. 2001, J. Geophys. Res.: Atmospheres, 106, 12067

[18] Ichoku C., Chu D. A., Mattoo S. et al. 2002, Geophys. Res. Lett., 29, 8006

[19] Kahn R. A., Gaitley B. J., Martonchik J. V. et al. 2005, J. Geophys. Res.: Atmospheres, 110, D10S04

[20] Kim D.-H., Sohn B.-J.; Nakajima T. et al. 2004, J. Geophys. Res.: Atmospheres, 109, D02209

[21] Kim S.-W., Yoon S.-Ch., Dutton E. G. et al. 2008, Aerosol Sci. Technol., 42, 1

[22] Kokhanovsky A. A., Davis A. B., Cairns B. et al. 2015, Earth-Science Rev., 145, 85

[23] Levelt P.F., van den Oord G. H. J., Dobber M.R. et al. 2006, IEEE Transactions on Geoscience and Remote Sensing, 44, 1093

[24] Marbach T., Phillips P. \& Schlüssel P. 2013, AIP Conf. Proc., 1531, 344

[25] McPeters R., Kroon M., Labow G. et al. 2008, J. Geophys. Res., 113, D15S14

[26] Mielonen T., Arola A., Komppula M. et al. 2009, Geophys. Res. Lett., 36, L18804

[27] Milinevsky G., Danylevsky V., Bovchaliuk V. et al. 2014, Atmospheric Measurement Techniques, 7, 1459

[28] Milinevsky G. P., Danylevsky V. O., Grytsai A. V. et al. 2012, Advances in Astronomy and Space Physics, 2, 114

[29] Mishchenko M. I., Cairns B., Kopp G. et al. 2007, Bull. 


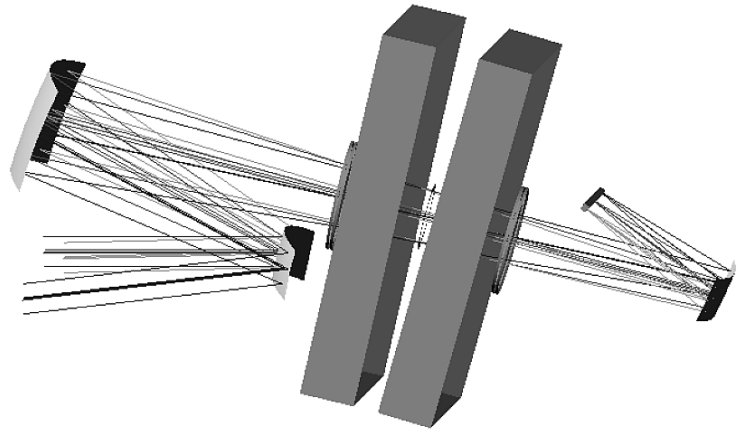

Fig. 1: Multiangle SpectroPolarimetric Imager (MSPI) optical layout: three mirror off-axis reflector telescope, $1 / 4$ wave retardance modulator, and dual piezoelastic modulators PEM (in the middle) $[8,33]$.

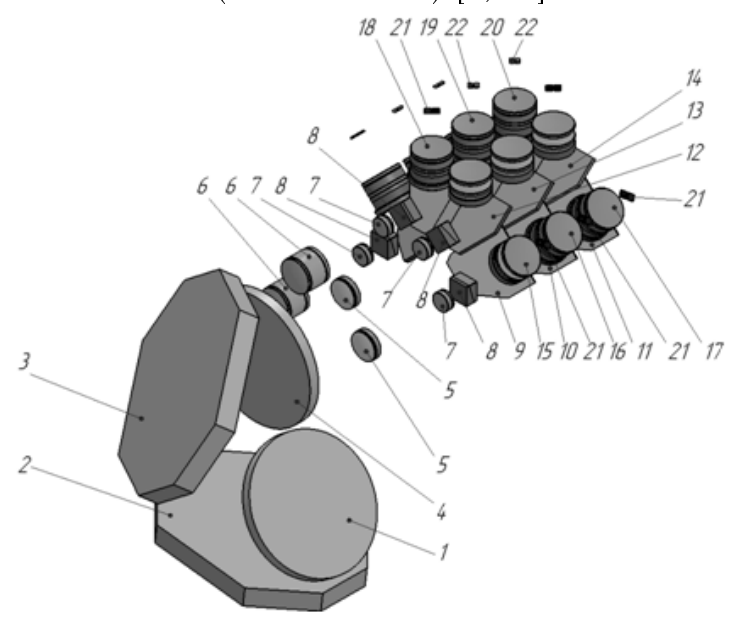

Fig. 3: ScanPol polarimeter optical layout: 1-4 - mirror scanning system, 5 - input lens of VIS spectral channel, 6 - input lens of the IR spectral channel, 7 - collimator, 8 Wollaston prism, 9-14 - dichroic mirrors, 15-20 - camera lens and interferential filters for spectral channels, 21 VIS sensors, 22 - IR sensors.

American Meteorological Soc., 88, 677

[30] 'NRC - National Research Council: Committee on Earth Science and Applications from Space: Earth Science and Applications from Space: National Imperatives for the Next Decade and Beyond'. 2007, The National Academies Press, Washington

[31] Omar A. H., Winker D. M., Tackett J. L. et al. 2013, J. Geophys. Res.: Atmospheres, 118, 4748

[32] Pappalardo G., Amodeo A., Apituley A. et al. 2014, Atmospheric Measurement Techniques, 7, 2389

[33] Shi Y., Zhang J., Reid J.S. et al. 2011, Atmospheric Chemistry and Physics, 11, 557

[34] Smirnov A., Holben B. N., Giles D. M. et al. 2011, Atmospheric Measurement Techniques, 4, 583

[35] Smit J. M., Rietjens J. H. H., Hasekamp O. et al. 2012,

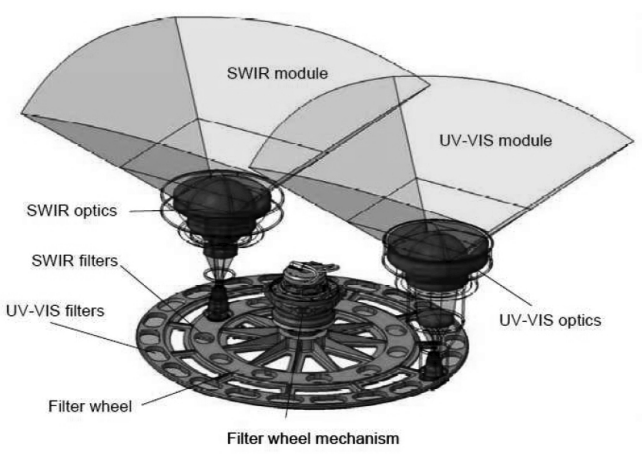

Fig. 2: Concept of 3MI instrument: concentric filter ring wheel with filters for the UV-VIS and SWIR ranges feed by two telescopes with field-of-view of $\pm 55^{\circ}$ [1].

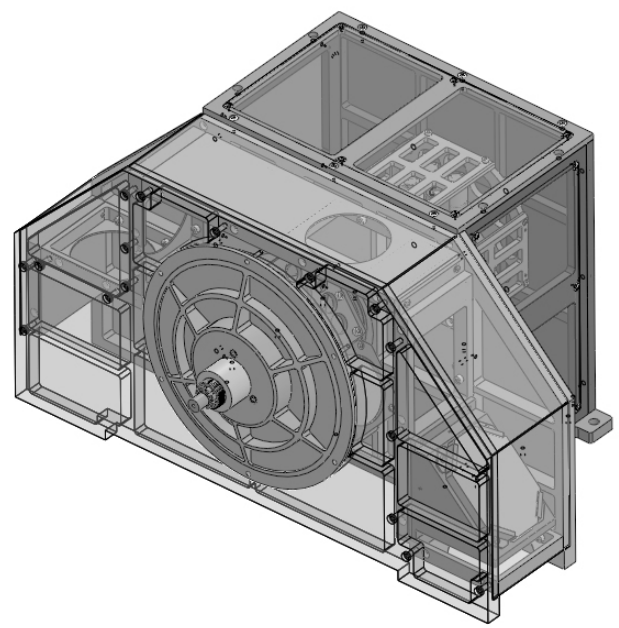

Fig. 4: ScanPol unit (on the back) assembled with mirror scanning system (in front) general view. The mirror rotating motor is not shown. Design for airplane test measurements.

EGU General Assembly 2012, 14166

[36] Snik F., Karalidi T. \& Keller C. U. 2009, Appl. Opt., 48, 1337

[37] Tanré D., Bréon F. M., Deuzé J. L. et al. 2011，Atmospheric Measurement Techniques, 4, 1383

[38] 'The need for aerosol and cloud measurements from space: essential contributions from a rapid reflight of the Aerosol Polarimetry Sensor', eds.: Cairns B. \& Mishchenko M. 2012, NASA Goddard Institute for Space Studies, New York

[39] van Harten G., Snik F., Rietjens J. H. H. et al. 2011, Proc. SPIE, 8160, 81600Z

[40] Yatskiv Ya.S., Mishchenko M. I., Rosenbush V. K. et al. 2012, Space Science and Technology, 18, 4, 3 